\title{
Role of Computed Tomography in the Evaluation of Patients with Maxillofacial Trauma
}

\author{
Deepak Yadavi*, Amit Jha ${ }^{2}$, Sadhan Mukhi ${ }^{3}$, Shashank Tripathi' ${ }^{1}$, Ravish Mishra' ${ }^{1}$ Laxmi Kandel ${ }^{1}$ \\ ${ }^{1}$ Department Of Oral \& Maxillofacial Surgery, Universal College of Medical Sciences, Nepal \\ ${ }^{2}$ Department of Radiodiagnosis, Nepalgunj Medical College, Kohalpur, Nepal \\ ${ }^{3}$ Department of Radiodiagnosis, Universal College of Medical Sciences, Nepal
}

*Corresponding author: Deepak Yadav, Department of Maxillofacial Surgery, Universal College of Medical Sciences, Bhairahawa, Nepal

\begin{abstract}
Introduction: Maxillofacial injuries are one of the most frequently encountered cases accounting for a large proportion of patients in emergency department. Multidetector Computed tomography (MDCT) is now an important imaging tool for evaluating maxillofacial trauma, having largely replaced plain radiographs due to its ability to detect the exact site, number and extent of fractures as well as added advantages of 3D reconstruction and multiplanar reformatting.

Objective: This study was performed to assess the role of MDCT in patients of maxillofacial trauma and to describe the demographic variations as well as frequency and types of fractures that underwent CT scans.

Materials and methods: Maxillofacial trauma patient sent for needful CT scan from emergency room to Department of Radiology from September 2015 to March 2017 were included in the study. Total of 50 cases were included. Following parameters were obtained: age, sex, time of injury, cause of injury, history of LOC (loss of consciousness), influence of alcohol and presence and type of fractures. The imaging findings were studied, multiplanar reconstructions were performed in all cases using high resolution bone window and soft tissue window, as well as 3D reconstructions and fractures were identified and classified.

Results: There were 42 male and 8 female patients, the majority of whom were below 40 years of age. Most injuries occurred during evening (36\%) and the most common cause of injuries in our study was road traffic accidents (44\%), physical assault (32\%), fall from height (20\%) and sport injuries (4\%). 70\% patients had RTA under the influence of alcohol. Motorbike accidents were common (55\%) in RTA patients. $44 \%$ had loss of consciousness following trauma. Out of 50 patients, 48 patients had total of 102 fractures while the rest 2 had minor soft tissue injuries. The frequency and types of fracture was as follows: maxillary sinus wall fracture $(20.6 \%)$ followed by orbital floor fractures $(16.6 \%)$, nasal fractures $(14.7 \%)$, mandibular fractures $(11.7 \%)$, tripod fractures (8.8\%), isolated zygomatic arch fractures (7.8\%), le fort fractures (6.8\%), orbital wall fractures (4.9\%), NOE complex fractures $(2.9 \%)$, dento-alveolar fractures of maxilla $(1.9 \%)$ and other fractures $(2.9 \%)$.
\end{abstract}

Conclusion: Maxillofacial trauma is one of the most common emergency requiring accurate and early diagnosis. MDCT is useful diagnostic tool for the identification and classification of maxillofacial region fractures and aiding in surgical planning.

Keywords: Maxillofacial trauma, MDCT, fractures

\section{Introduction}

Maxillofacial injuries are one of the most frequently encountered emergencies accounting for a large proportion of patients in emergency department [1,2]. Maxillofacial injuries occur quite commonly following trauma and these injuries if not properly managed can negatively influence aesthetic, functional and psychosocial activities of the patient [3]. Facial region is one of the complex region of the human body anatomically. Several bones coupled with superimposition over one another makes it even more difficult to identify individual bones and accordingly classify fractures, however there are some organizational principles that can help guide for accurate evaluation of facial injury. 
The face can be organized into five distinct anatomic regions: nasal, orbital, zygomatic, maxillary and mandibular. Injuries to the face can be classified as those related to a single region; disparate regions; or multiple contiguous regions (e.g., midface smash or panfacial fractures). The growing frequency and magnitude of road traffic accidents, as well as the increase in episodes of urban violence, have made these traumas a form of social disease [4]. Now-a-days injuries due to road traffic accidents and violence are the common reasons which has significantly led to the increase in the frequency of maxillofacial injuries [4,5]. Other causes of injury to maxillofacial region include fall and sports injury. Plain radiography has limited role in imaging trauma patients as it provides inadequate information due to complexity of facial anatomy. CT scan has completely replaced plain radiographs for the investigation of choice in a case of maxillofacial trauma. The CT examination provide adequate radiographic assessment for facial bones like orbit, midface and nasoethmoid region while it will not add more information than conventional imaging in mandibular area except the condyle area.

Computed tomography is the imaging method of choice for an accurate diagnosis and for depicting the complex anatomic structures of the maxillofacial region and now regarded as gold standard in a case of maxillofacial trauma. It helps in detecting the exact site, number and extent of fractures, displacement of fragments and soft tissue injuries $[2,4,5]$. The added advantage of MDCT is 3-D reconstruction and multiplanar reformation in coronal and sagittal planes which are extremely helpful in assessing the bony architecture in large comminuted, displaced and complex fractures involving multiple planes [6] helps the surgeons for appropriate planning and management.

Hence, the present study is aimed to evaluate the role of CT in maxillofacial trauma patients.

\section{Materials and Methods}

A descriptive, cross sectional hospital-based study conducted from September 2015 to March 2017 in Universal College of Medical Sciences - Teaching Hospital (UCMS-TH), Bhairahawa, Nepal. The study includes 50 cases with patients with maxillofacial trauma referred for CT scan of head and face. The study was done using a General Electronics (GE) Brivo® 38516 slice helical CT scanner. CT face was performed with patient in supine position and axial slices were taken at $0.625 \mathrm{~mm}$ collimation with field of view extending from the top of frontal sinuses to the chin. The supine axial slices were taken for fast acquisition and comfort to the patient and the images were also reconstructed in coronal and sagittal plane for examination.

The images were primarily studied in bone window (WL 300 WW 1500), Soft tissue window (WL 40, WW 400) as well as 3D reconstructions with other windows being used where relevant. Intravenous iodinated contrast media was not used in this study.
Fractures found were classified into the following groups: maxillary sinus wall fractures, nasal fractures, nasoethmoidal fractures, fractures of the zygomatic-malar complex, isolated zygomatic arch fractures, orbital floor fractures, orbital roof fractures, maxillary, mandibular, Le Fort fractures and other sort of fractures. The results were tabulated in Microsoft Excel. The statistical analysis was done using Statistical Package for the Social Sciences (SPSS).

\section{Inclusion criteria}

a) No emergency treatment is needed according to the advance trauma life Support (ATLS).

b) Patients with multiple facial injuries or severe facial disfigurement.

c) Patients with craniofacial or cervical injuries.

d) In cooperative patients or altered in the level of consciousness.

\section{Exclusion criteria}

a) Patients who are unstable and require emergency treatment according to Advance Trauma Life Support (ATLS)

b) Patients who refuse to give consent.

c) Patients with past $\mathrm{H} / \mathrm{O}$ maxillofacial surgery or intervention.

d) Dead on arrival.

e) Fractures that can be easily ruled out by plain radiographs.

f) Suspected isolated fracture of mandible.

Proper ethical clearance was obtained from the institution before conducting the study.

\section{Results}

A total of 50 subjects of maxillofacial trauma patients were included in the present study. The maximum number of trauma patients fall into 21-40 years age group whereas minimal number were from 61-80 years age group as shown in Figure 1. The selected group include 42 males (84\%) and 8 females (16\%) as shown in Figure 2 . The time of injury occur mostly at evening time (18\%) followed by night-time (13\%) as shown in Figure 3. The mode of trauma were from RTA (44\%) followed by physical assault (32\%), fall from height (20\%) and sports injuries (4\%) as shown in Figure 4. In RTA, motorbike accident (55\%) was most prevalent followed by bus $(23 \%)$ and rickshaw (14\%) as shown in figure 5 . Loss of consciousness were present in $56 \%$ of patients as shown in Figure 6. $34 \%$ of patients with maxillofacial fracture were found to be under the influence of alcohol shown in Figure 7. Maxillary bone fracture $(20.65 \%)$ were most prevalent followed by orbital floor fracture $(16.66 \%)$ and mandibular fractures (11.75\%) as shown in Table 1. 


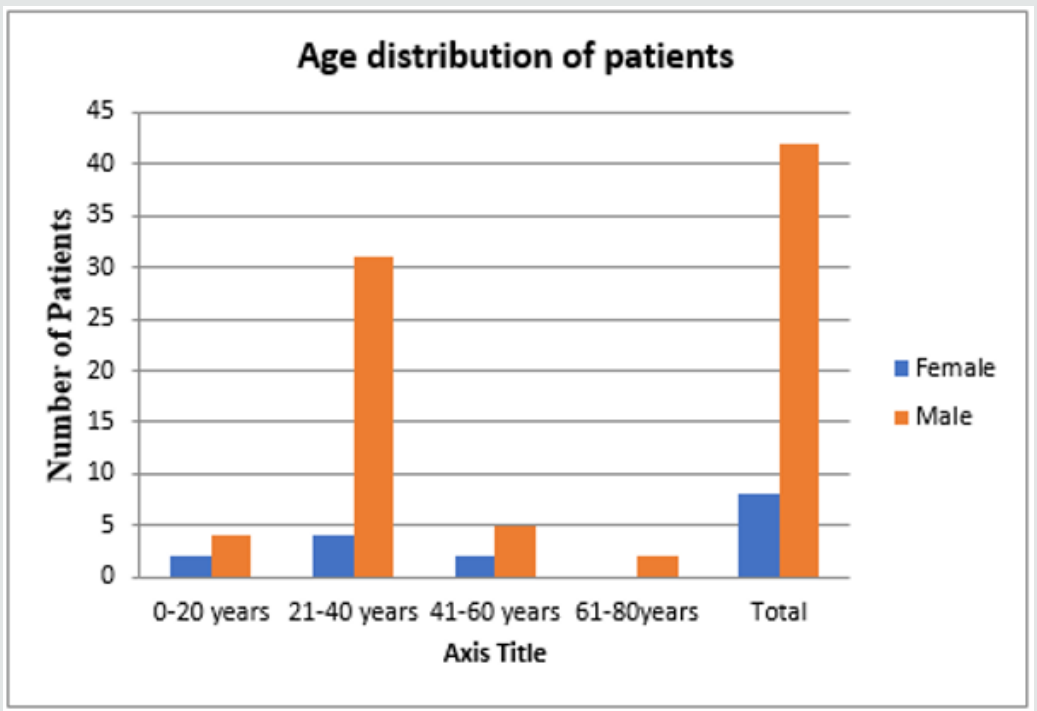

Figure 1: Age distribution of patients.

\section{Gender distribution $(\mathbf{n}=50)$}

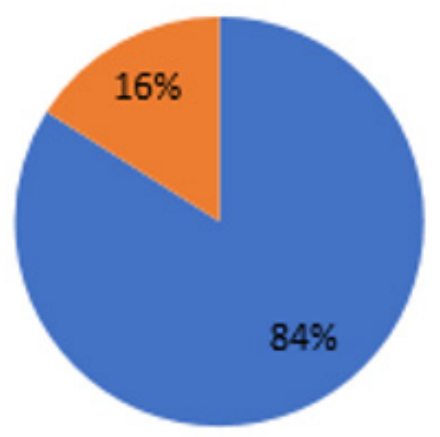

Figure 2: Gender distribution of patients.

\section{Number of patients $(n=50)$}

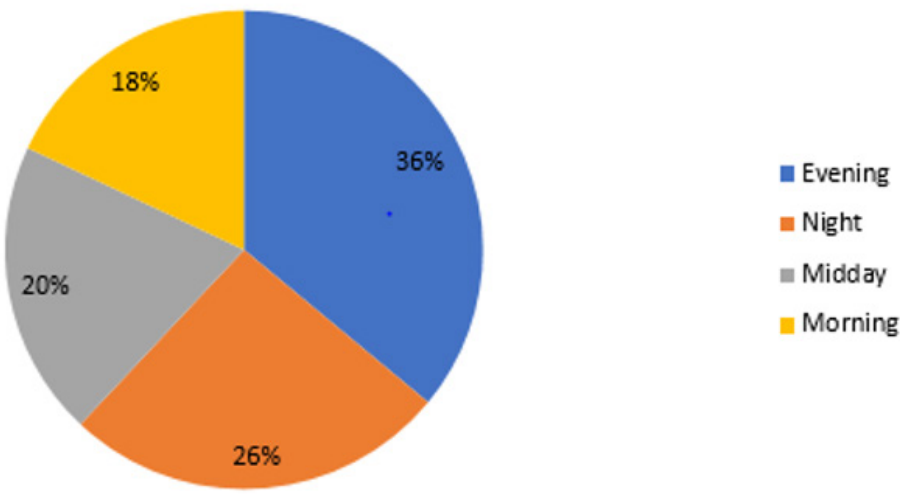

Figure 3: Time of distribution of patients at the time of injury. 


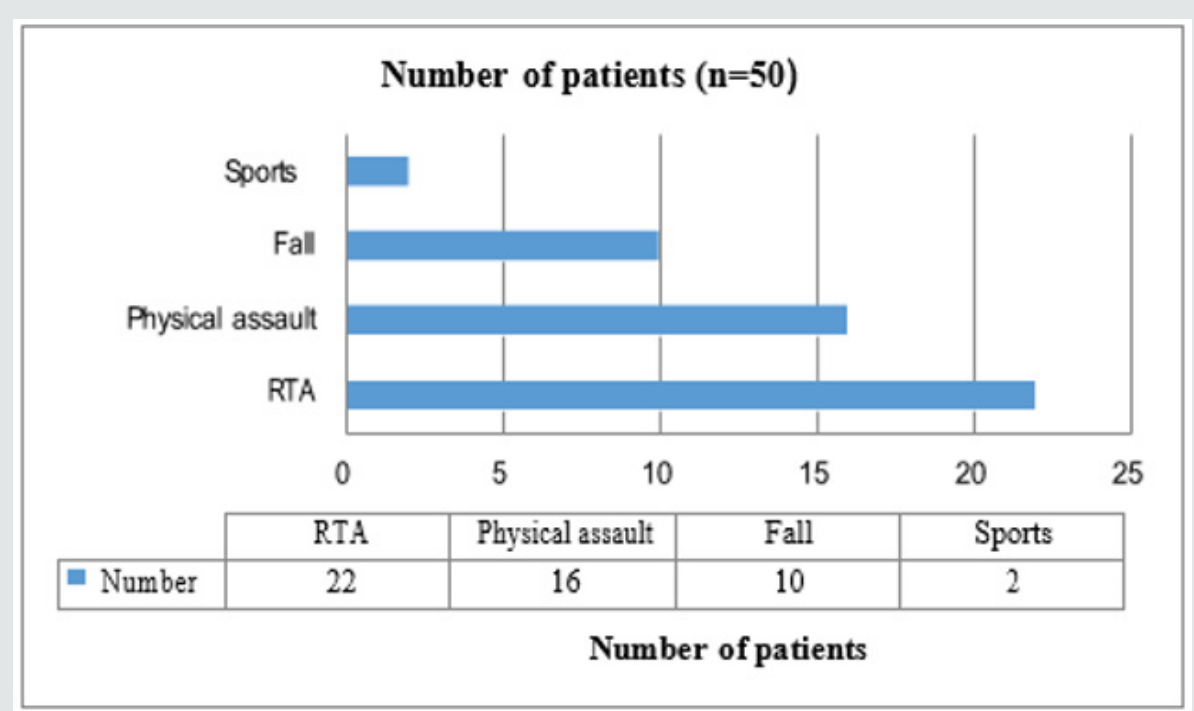

Figure 4: Frequency of patients according to mode of injury.

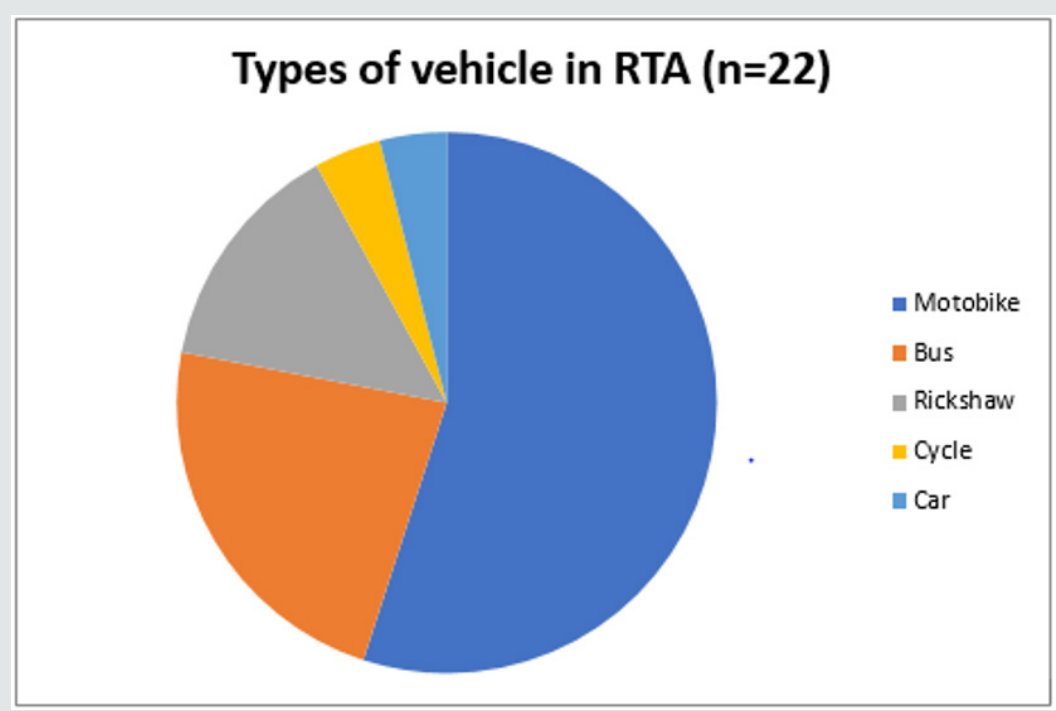

Figure 5: Distribution of patients according to the type of vehicle used in RTA.

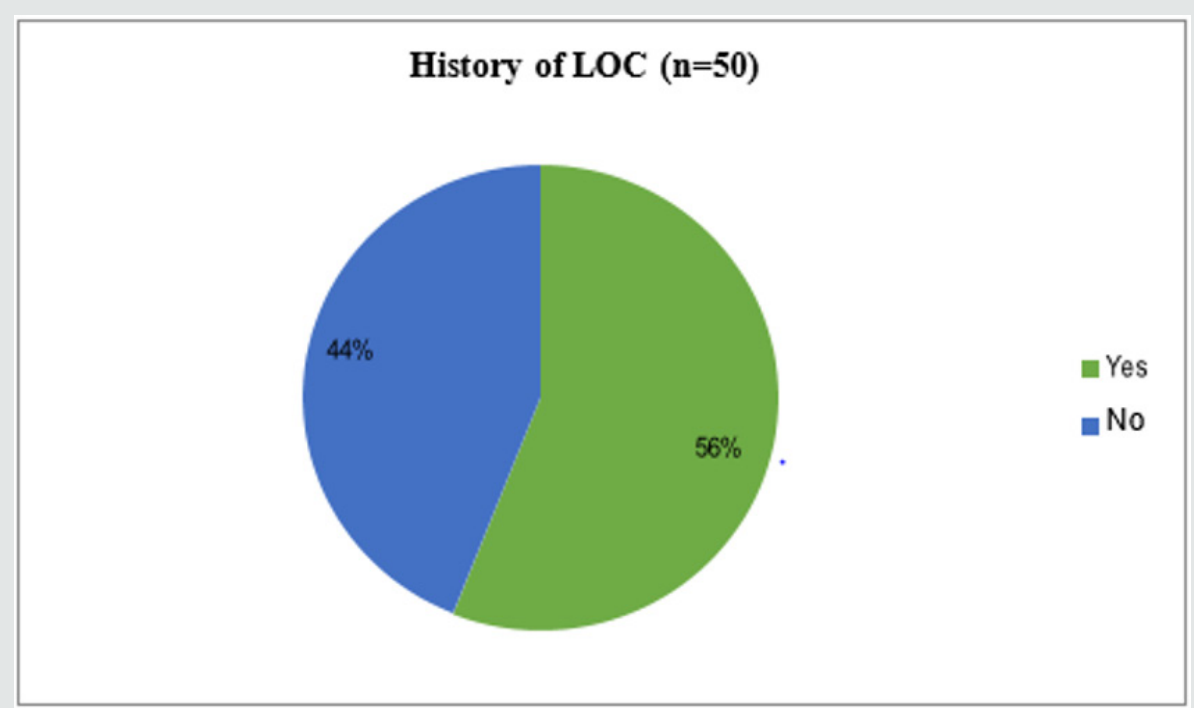

Figure 6: Distribution of patients based of loss of consciousness. 


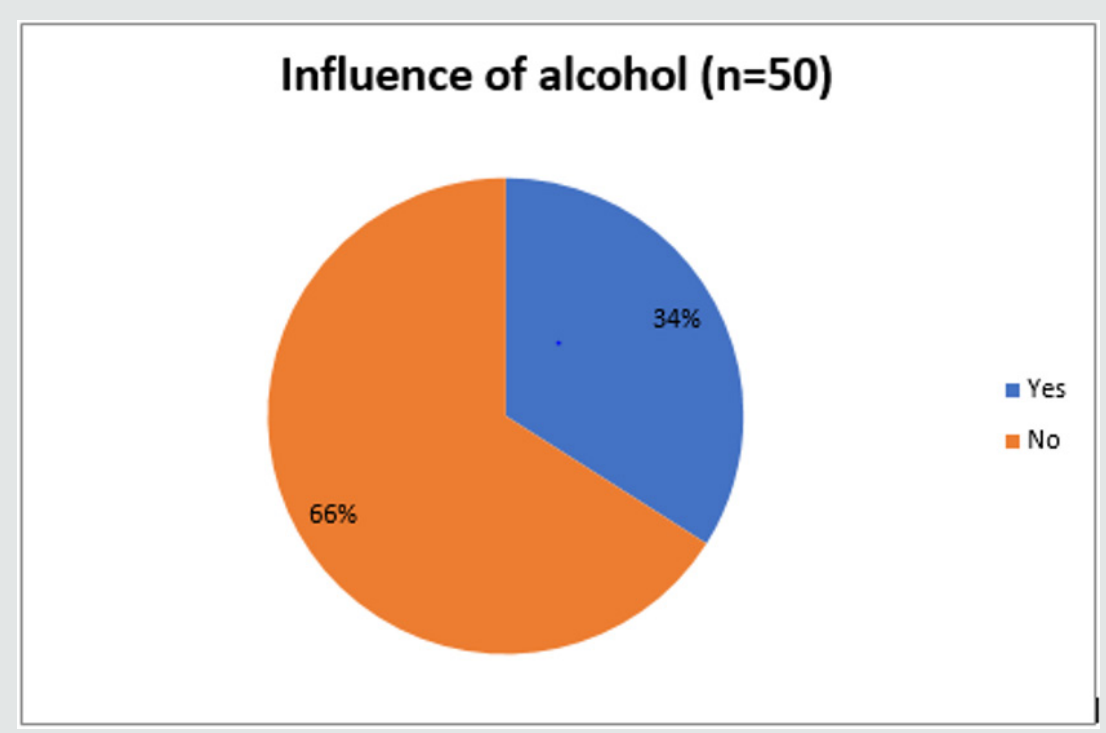

Figure 7: Frequency of patients based on influence of alcohol.

Table 1: Frequency wise distribution of maxillofacial fractures.

\begin{tabular}{|c|c|c|c|}
\hline \multicolumn{2}{|c|}{ Type of Fracture } & Number & Percent (\%) \\
\hline & $\begin{array}{c}\text { Maxillary sinus wall } \\
\text { fractures }\end{array}$ & 21 & 20.65 \\
\hline Maxilla & Le fort fracture & 7 & 6.85 \\
\hline $\begin{array}{c}\text { Dento-alveolar } \\
\text { fractures }\end{array}$ & 2 & 1.96 \\
\hline Orbital floor fractures & 17 & 16.66 \\
\hline Nasal fractures & 15 & 14.7 \\
\hline Mandibular fractures & 12 & 11.75 \\
\hline Tripod fractures & 9 & 8.81 \\
\hline Zygomatic fractures & 8 & 7.84 \\
\hline Orbital wall fractures & 5 & 4.9 \\
\hline NOE Complex fractures & 3 & 2.94 \\
\hline Others & 3 & 2.94 \\
\hline Total & 102 & 100 \\
\hline
\end{tabular}

\section{Discussion}

The present cross-sectional study was designed to identify the demographic variables and classify fractures accordingly in cases of maxillofacial trauma by the use of CT scan. CT is the imaging method of choice for an accurate diagnosis and for depicting the complex anatomic structures of the maxillofacial skeleton.

Various studies have been conducted to identify and classify fractures of the maxillofacial region. While there are some significant differences in the findings of studies done by different researchers at different time intervals. The present study consisted of 50 patients with maxillofacial trauma that were referred for CT face. Various imaging findings ranging from simple linear to comminuted fractures with severe disfigurement of face. Out of 50 cases, 42 were male (84\%) and 8 were female (16\%). The mean age of the patient was 29.9 years which was incoherent to study done by Kaleem Ahmad et al. [7], Haug RH et al. [8] Tanaka et al. [9] and Rajib Khadka et al. [10].
The male: female ratio was 2.5:1 which was similar to the study done by Kaleem Ahmad et al. [7], Salonen EM [11] and Rajib Khadka et al. [10].

In the present study, most of the injuries were seen occurring during evening time (36\%). The most common mode of injury was found to be RTA (44\%), followed by physical assault (32\%) patients. The main reasons for RTA in country like Nepal are due to narrow lane road, hilly areas and poorly constructed road. Out of which most of the RTA occurred particularly involving motorbike (55\%) followed by bus (23\%) and bicycle (14\%). Motorbike is one of the major source of transport in Nepal as Nepal is low income country and its easy to travel with motorbike in hilly areas. Out of 22 patients involved in RTA, alcohol by any means was found to be involving in 12 patients (54.54\%) which is in accordance with study conducted by V. Ravindran et al. [12], Gabriela Tomlich et al. [13], Shrisail Patil et al. [14], Subhasraj K et al. [15], Rajib khadka et al. [10].

Out of 50 patients who underwent CT face, 48 had fractures either single or multiple. The total number of fractures recorded were 102. By far the commonest fracture on CT was maxillary sinus wall fracture $(20.65 \%)$ followed by followed by orbital floor fractures $(16.6 \%)$, nasal fractures $(14.7 \%)$, mandibular fractures $(11.7 \%)$, tripod fractures $(8.8 \%)$, isolated zygomatic arch fractures (7.8\%), Le Fort fractures (6.8\%), orbital wall fractures $(4.9 \%)$, NOE complex fractures $(2.9 \%)$, dento-alveolar fractures of maxilla $(1.9 \%)$ and other fractures $(2.9 \%)$ which was similar to study done by Gabriela Tomlich et al. [13], Kaleem Ahmad et al. [7], Shrisail Patil et al. [14].

Both axial and coronal scan were found to be beneficial in localizing and identifying maxillofacial fractures in detail. Qais $\mathrm{H}$ Muassa et al. [16] in their literature revealed that 42 (46.7\%) fractures out of 92 were detected by coronal scans while 28 (30.4\%) fractures were detected by axial scans. When combined the rest 21 (22.8\%) were detected. 


\section{Conclusion}

Maxillofacial injuries are commonly encountered emergencies which needs early diagnosis and prompt management. The main purpose of diagnostic imaging is to detect and localize the exact number, site of facial fractures and to differentiate from soft tissue injuries so that proper treatment planning could be carried out. MDCT plays vital role in diagnosis and treatment planning of maxillofacial trauma but because of certain limitations i.e. small sample, low prevalence of maxillofacial trauma further studies with larger number of patients should be carried out to reach conclusive results.

\section{Disclosure}

None.

\section{References}

1. Mehta N, Butala P, Bernstein MP (2012) The imaging of maxillofacial trauma and its pertinence to surgical intervention. Radiologic Clinics of North America 50(1): 43-57.

2. Pathria MN, Blaser SI (1989) Diagnostic imaging of craniofacial fractures. Radiologic Clinics of North America 27(5): 839-53.

3. Yamamoto K, Matsusue Y, Horita S, Murakami K, Sugiura T, et al. (2014) Clinical analysis of midfacial fractures. Materia socio-medica. 26(1): 2125.

4. Thai KN, Hummel RP, Kitzmiller WJ, Luchette FA (1997) The role of computed tomographic scanning in the management of facial trauma. Journal of Trauma and Acute Care Surgery 43(2): 214-217.

5. Salvolini U. Traumatic (2002) injuries: imaging of facial injuries. EurRadiol 12(6): 1253-1261.
6. Som PM, Brandwein MS (2003) Facial fractures and postoperative findings. Head and neck imaging 374-438.

7. Ahmad K, Rauniyar RK, Gupta MK, Ansari S, Pant AR, et al. (2014) Multidetector computed tomographic evaluation of maxillofacial trauma. Asian Journal of Medical Sciences 5(4): 39-43.

8. Haug RH, Prather J, Indresano AT (1990) An epidemiologic survey of facial fractures and concomitant injuries. Journal of Oral and Maxillofacial Surgery 48(9): 926-32.

9. Tanaka N, Tomitsuka K, Shionoya K, et al. (1994) Aetiology of maxillofacial fracture. Brit J Maxillofac Surg 32(1): 19-23.

10. Khadka R, Chaurasia NK (2014) Four years prospective study of the maxillofacial trauma at a tertiary center in Western Nepal. Journal of Orofacial Sciences 6(2): 78-81.

11. Salonen EM, Koivikko MP, Koskinen SK (2010) Violence-related facial trauma: analysis of multidetector computed tomography findings of 727 patients. Dentomaxillofacial Radiol 39(2): 107-113.

12. Ravindran V, Ravindran Nair KS (2011) Metaanalysis of Maxillofacial Trauma in the Northern districts of Kerala: one year prospective study. J Maxillofacial oral Surg 10(4): 321-327.

13. Tomich G, Baigorria P, Orlando N, Méjico M, Costamagna C (2011) Frequency and types of fractures in maxillofacial traumas. Assessment using multi-slice computed tomography with multiplanar and threedimensional reconstructions. Rev Argent Radiol 75(4): 305-317.

14. Patil S, Melkundi SS (2015). Maxillofacial and orbital injuries evaluation by three dimensional MDCT. Journal of Evolution of Medical and Dental Sciences 4(72): 12470-12477.

15. Subhashraj K, Nandakumar N, Ravindran C (2007) Review of maxillofacial injuries in Chennai, India: a study of 2748 cases. British Journal of Oral and Maxillofacial Surgery 45(8): 637-639.

16. Qais H Muassa, Ibrahim Saeed Gataa (2009) The diagnostic value of Computed Tomography in evaluation of maxillofacial Trauma. Kufa Med Journal.

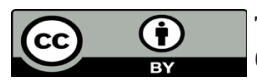

This work is licensed under Creative Commons Attribution 4.0 License

To Submit Your Article Click Here: Submit Article

DOI: $10.32474 /$ MADOHC.2019.03.000176

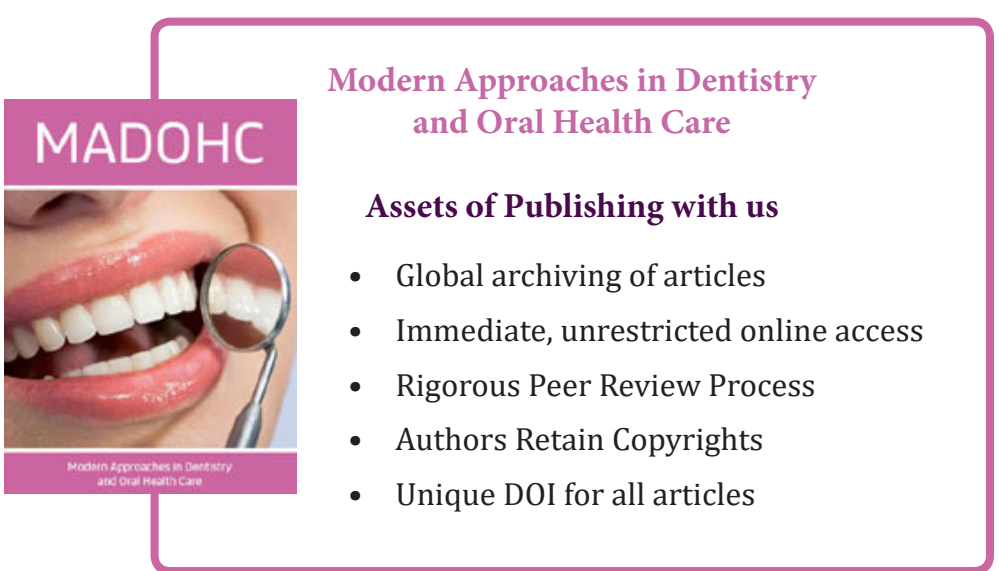

